\title{
A Predictive Database Model for Process Analysis in A Large Industrial Blast Furnace
}

\author{
Gaurav Kumar
}

\begin{abstract}
The current blast furnace iron making process, like any other large scale industrial process, is fully automated. This means that the whole process, right starting from raw materials handling to the final output product (and by-product) can be monitored and assessed live. However, most of the physical and chemical processes in blast furnace are irreversible. This means that once charging is done, the output of that particular charge is fixed (example, the hot metal composition, slag composition and basicity, composition of the top gases etc.).This means that any deviation from the desired properties of the output cannot be replenished. These deviations are a common trend and add a lot to the losses of the industries. It would be better if the output of a particular charge is pre-assessed and predicted so that one can understand and apply the necessary corrections, if required. Conventional automation may tell the live status of a process but it can do little to correct the deviation. This paper illustrates the functioning of a predictive database model capable of pre-calculating and assessing the material and heat balance, productivity, aerodynamic features, predicting the thermo-chemical status of the chemical reactions and heat losses in an industrial blast furnace.
\end{abstract}

Index Terms - Database, Blast Furnace, Mass Balance, Heat Balance, Aerodynamic Features

\section{INTRODUCTION}

Iron making process via blast furnace just like any other industrial process is fully automated. However, the processes involved in it are almost irreversible. This means that although the process parameters and sequences can be controlled but once an input is given, one can do little to regulate the output. In other words, for a given input, the output is predefined. So one needs something beyond just process control. For, Example if a given input is given but somehow it is realised that that the output will not be a good one then one can make the necessary corrections only in the next batch of input. But if there is a possible provision of having a predictable software/database (or an equivalent feature) then one may understand about the quality of the input much before actual charging is done. This paper presents that kind of a predictable database which can take the necessary input, compute the calculations regarding the mass and heat balance, aerodynamic features , slag basicity, geometry and extent of the deadman zone etc. The whole database is produced in MS-Access interactive application software developed by Microsoft) this application software manages, operates and represents data by its three major components: Table, Query and Forms. For this database for blast furnace operation, these 3 components (tables, forms and queries) are extensively used. Tables, Forms and queries

Gaurav Kumar, Department of Metallurgical and Materials Engineering, National Institute of Technology Durgapur,Durgapur,India. are inter-related and it is by this inter-relation of these three that the effective operation and final representation of data can be done.

The 3 components of MS-Access can be defined as:

TABLES: Takes the input of the program (given by the user) by specifying the column name and the data type.

QUERIES: Queries are a way for searching and compiling data from a table or other sister query and computing all the necessary calculations on the input values based on the given required formulas.

FORMS: Forms are the display section of access, the input values as well as the calculated output values are displayed in Forms.

So, here the existing input and output values of a large induatrial blast furnace is taken, The input values is fed into the predictive database of blast furnace. The output values so obtained from the database is validated against the existing output values from literature .So, in the later parts of the paper the various parts of the predictive database is discussed ( form now onwards in the later parts of the paper ,the predictive blast furnace database will be referred as p_bf_database )

\section{STARTING THE P_BF_DATABASE}

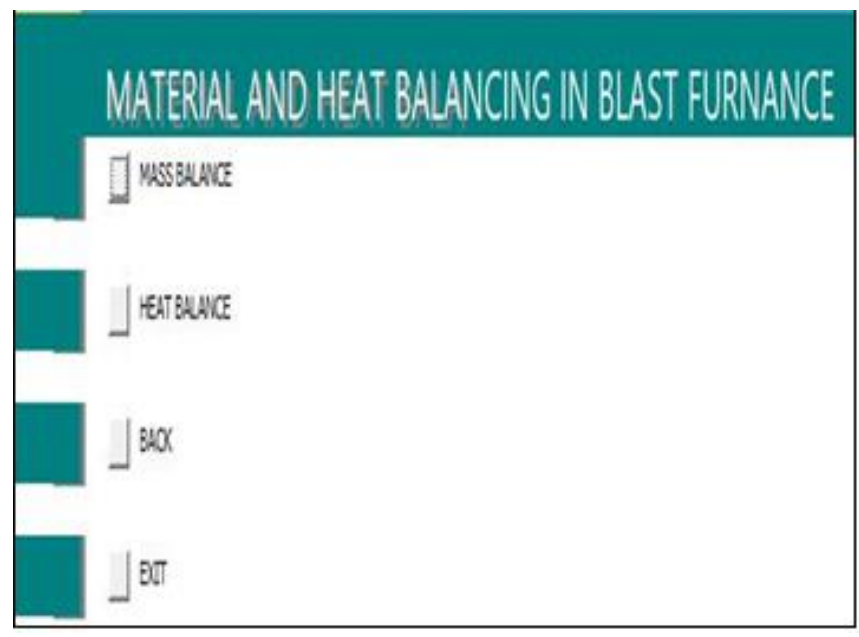

Fig-1

This is the starting part of the p_bf_database. It is actually a "FORM" of MS-Access. FORMS are generally used to represent the data in a user friendly and interactive manner .It can be seen that there are four options: MASS BALANCE, HEAT BALANCE and EXIT. The following flow chart depicts the various parts of MASS and HEAT BALANCE 


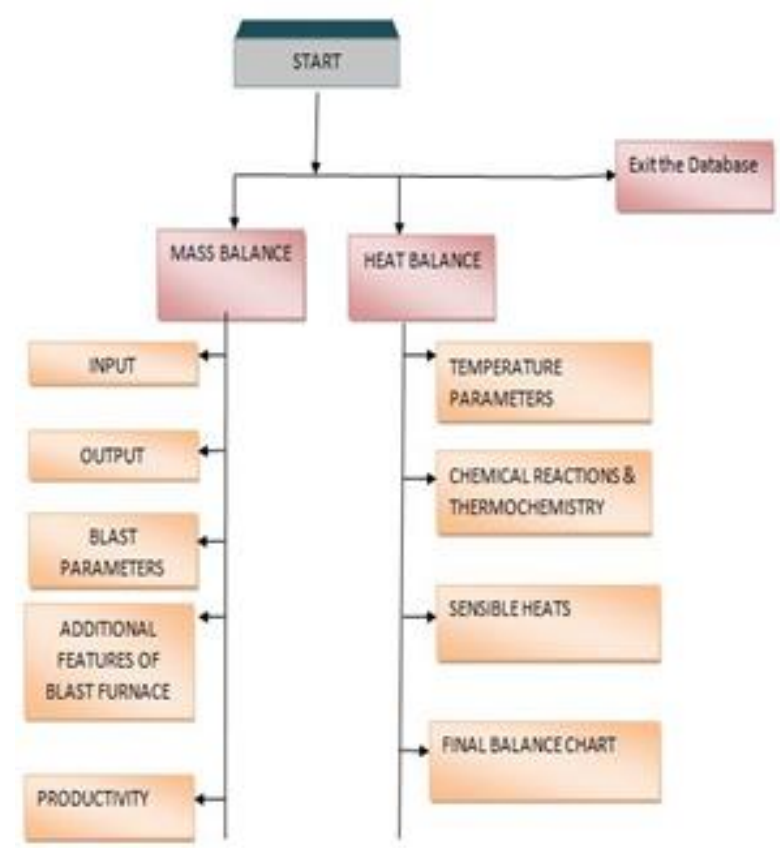

Fig-2

2.1 MASS BALANCING

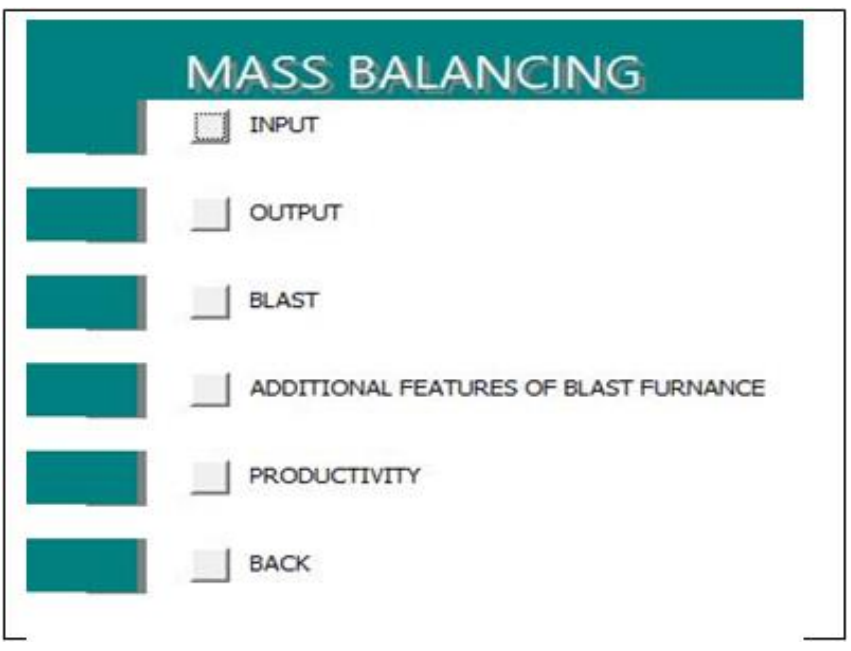

Fig-3

The MASS BALANCE contains the options of:

a. INPUT: This option takes from the user the required input values required for the mass balance calculations
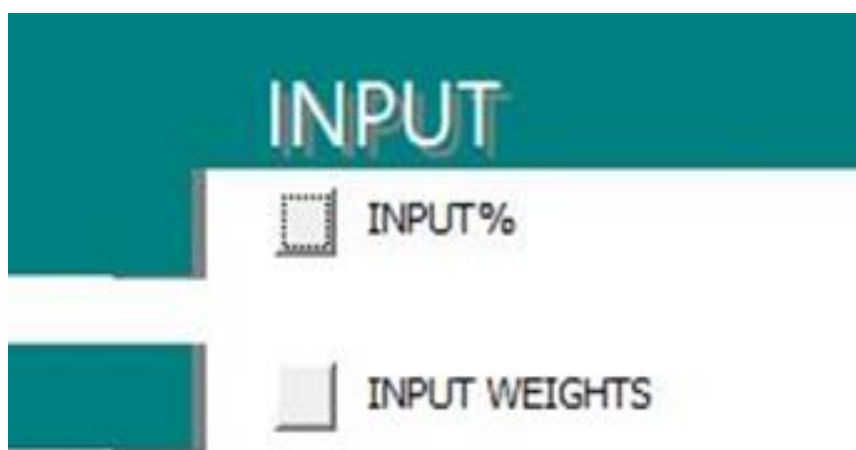

\section{INPUT WEIGHTS}

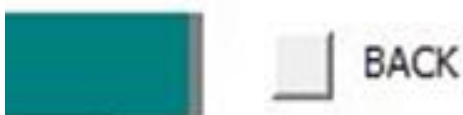

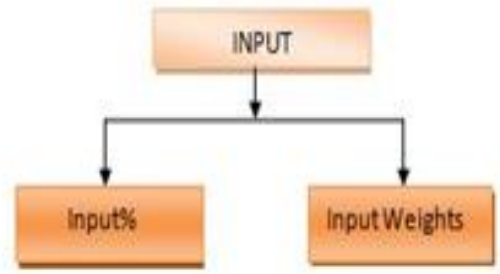

Fig-5

INPUT is taken in two parameters: Input\% and Input weights. This means one need to give the weight of one type of input as well as its individual composition.

b. OUTPUT
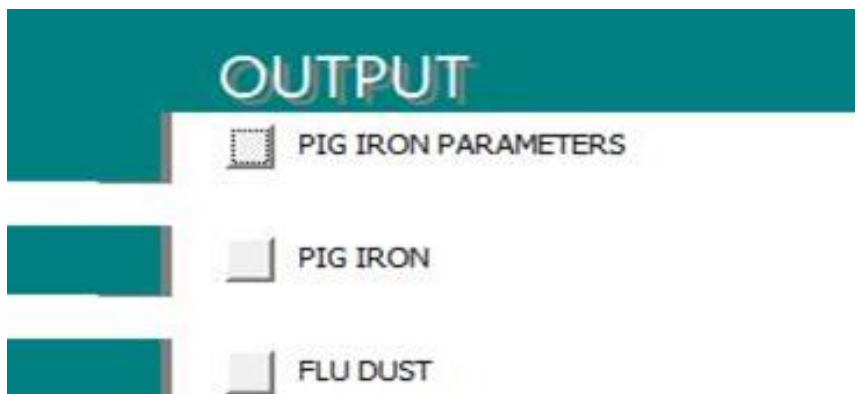

1 PIG IRON
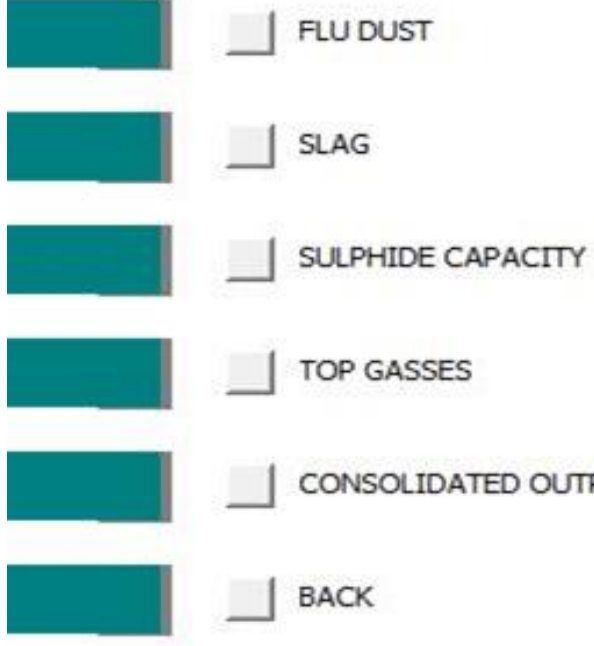

BACK

Fig-6

This option displays the relevant output data; the user only needs to provide here the necessary "PIG IRON PARAMETERS" i.e. the user needs to provide the fraction of Sulphur, Silicon, and Manganese entering the PIG Iron. Then the user will be able to see:

b.1: Amount (in tons), composition, density, surface tension and melting point of the PIG IRON (For the given Input)

b.2: Amount (in tons) and Composition of FLU Dust

b.3: Amount (in tons), composition and Basicity of slag

b.4: Sulphide Capacity

b.5: Amount (in tons) and composition of the top gasses, and also the combustion information (like the fraction of carbon burned in tuyeres).

b.6 a consolidated output of PIG IRON, SLAG, FLU DUST and TOP GASSES.

Fig-4 


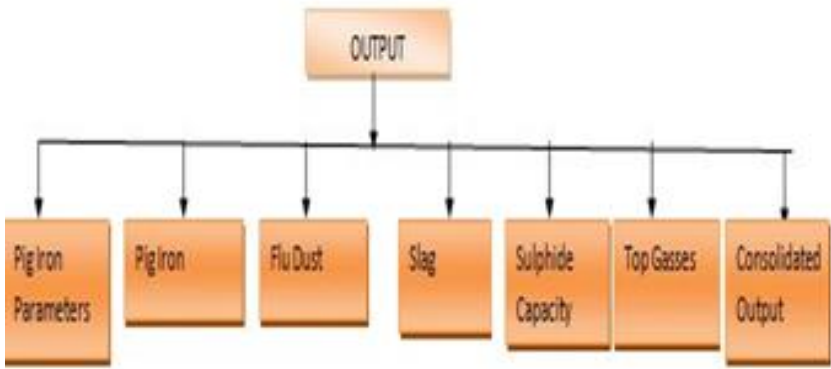

Fig-7

\section{c. BLAST PARAMETERS}

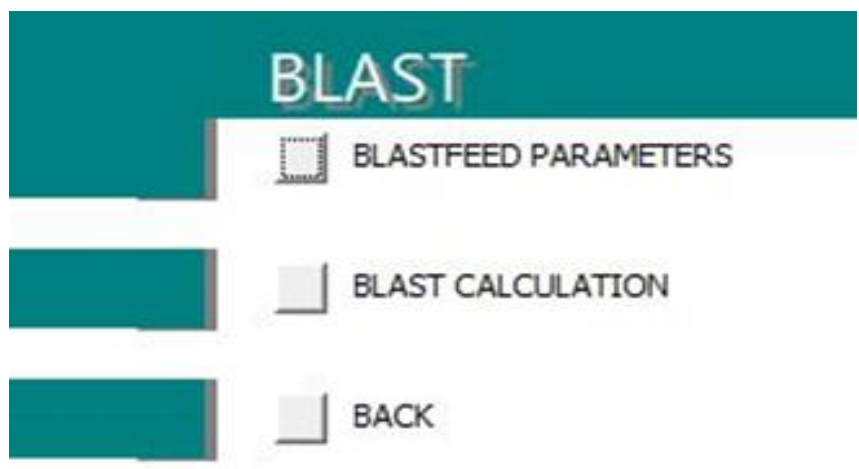

Fig-8

Here the required value of the blast moisture and blast temperature needs to be entered and then the mass balance analysis related to blast can be viewed.

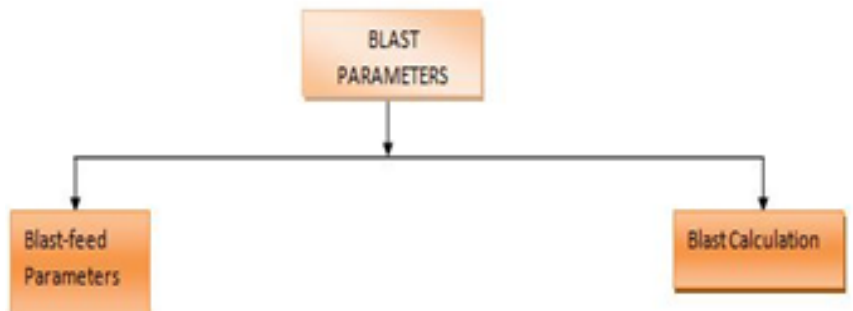

Fig-9

\section{d. ADDITIONAL FEATURES OF THE BLAST FURNACE}
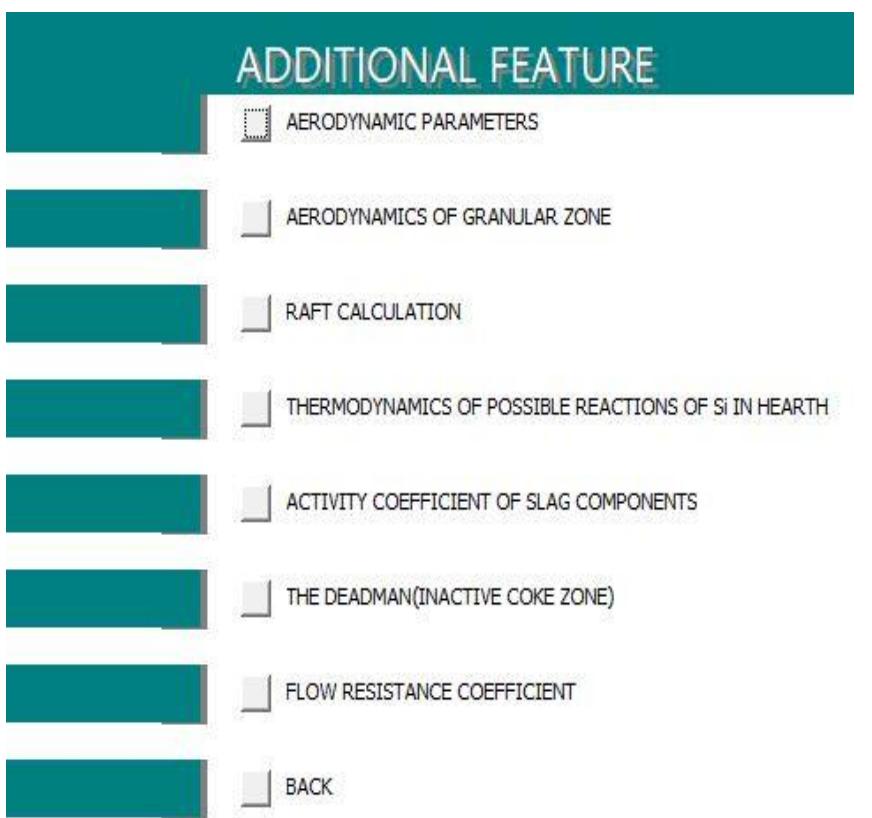

Fig-10
This is a very important part of the blast furnace analysis .Here the user is required to enter the required aerodynamic parameters like Nominal velocity of the gas through bed; temperature of the bed; bed void fraction; average density of ore, coke and flux, average, smallest and largest size of ore and the temperature of the stack, Then the user can see the following:

d.1 The aerodynamic features of the blast furnace's granular zone

d.2 RAFT (Raceway Adiabatic Flame Temperature) calculations

d.3 Thermodynamics of possible reactions in hearth d.4 Activity coefficients of slag components ( like Mn, Si,C) d.5 The Deadman Zone d.6 Flow Resistance Co-efficient(FRC)

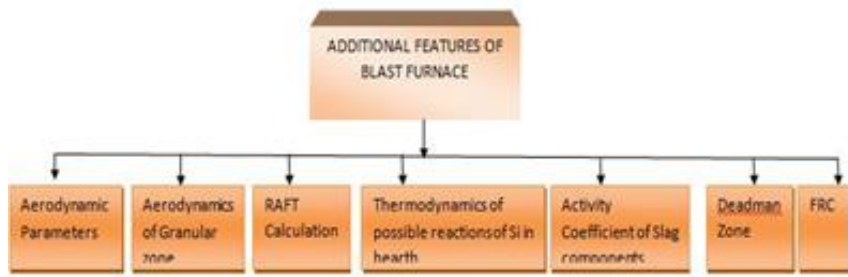

Fig-11

PRODUCTIVITY: Here based on the input values, the productivity of the blast furnace is calculated in terms of (thm $/ \mathrm{m}^{3} /$ day) i.e. tonnes of hot metal per cubic meter per day [1].

\subsection{HEAT BALANCING}

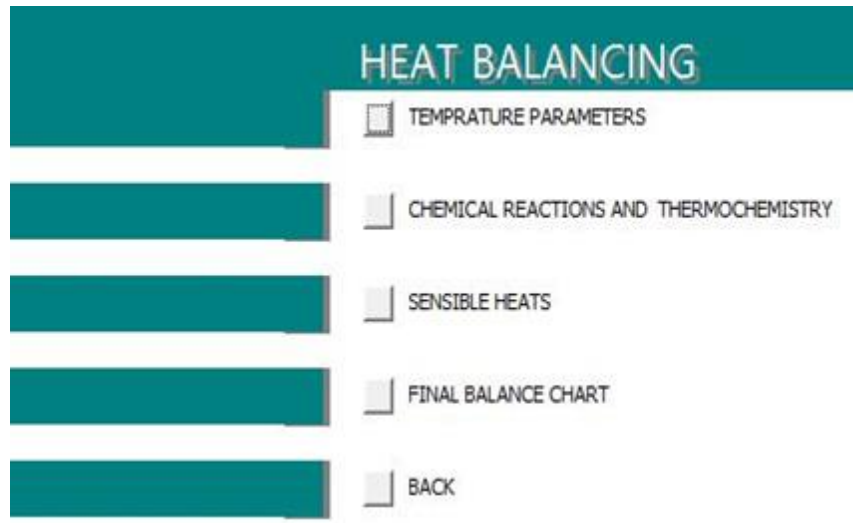

Fig-12

a. Temperature Parameters: Here the User needs to enter the known temperature values of Preheated blast, solid charge, slag and the reference temperature (these data are required for further thermo-chemical calculations).

b. Chemical reactions and thermo-chemistry: Here, on the basis of the previous input provided, one will be able to see the thermo-chemical calculations of almost all important chemical reactions taking place in various parts of the blast furnace

c. Sensible heats: Here, on the basis of the given input data , the sensible heats of all possible chemical reactions in Pre-heated moist blast, Pig Iron, Slag and Flu-Dust can be seen 


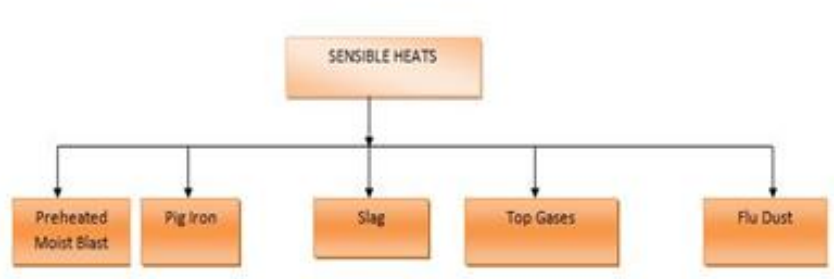

Fig-13

d. Final Balance: Here the final heat balance displaying the total heat input and heat output can be seen. In this balance chart the total heat loss of the blast furnace can also be observed.

\section{ADDITIONAL FEATURES OF BLAST FURNACE}

There are various internal aspects of the blast furnace which should be observed in order to see the whether the blast furnace is working in healthy condition or not. Those aspects are being illustrated as follows:

3.1 AERODYNAMICS OF THE GRANULAR ZONE: One important feature is the aerodynamics of the granular zone of the blast furnace. This analysis is done on the basis of Ergun's Model [1]. According to Ergun's Model states: Ergun equation is stated as $Y=\frac{150}{R e}+1.75$

For turbulent flow (Re>2000) equation becomes $Y=1.75-$ (1). Where $\mathrm{Y}$ is the friction factor and Re is the Reynolds number. Also $Y=\Delta P \cdot \frac{\rho_{g}}{G^{2}} \times \frac{D}{H} \times \frac{\epsilon^{3}}{1-\epsilon}$--- (2) Where $\rho_{g}$ : density of the gas mixture, D: particle diameter, $\mathrm{H}$ : bed height, $\epsilon$ :void fraction of packed bed, G:mass velocity of gas so $\mathrm{G}=\rho_{g} \cdot \mathrm{v}$ where $\mathrm{v}$ is the nominal velocity of gas. Now equating (1) with (2) we can get $\frac{\Delta P}{H}=1.75\left(\frac{G^{2}}{\rho_{g}}\right) \cdot\left(\frac{D}{H}\right) \cdot\left(\frac{1-\mathrm{E}}{\mathrm{E}^{\mathrm{g}}}\right)$, Where $\frac{\Delta P}{H}$ is the pressure drop per unit height. Critical bed fluidisation velocity Vc is attained when the pressure drop becomes equal to the overlying bed weight. Its expression is $V_{c}=\left(\frac{1}{1.75}\right)\left(\frac{\left(\rho_{s}-\rho_{g}\right)}{\rho_{g}}\right) D \cdot \epsilon^{3}$ where $\rho_{s}$ is density of solid.

3.2 RAFT CALCULATION: Another important feature is the calculation of RAFT (Raceway Adiabatic Flame Temperature): The following formula (Used by Nippon steel,

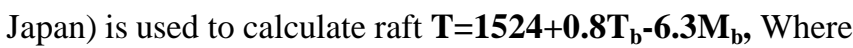
$\mathrm{T}$ :is RAFT temperature, $\mathrm{T}_{\mathrm{b}}$ :is blast temperature, $\mathrm{M}_{\mathrm{b}}$ :is moisture content [1].

\subsection{ACTIVITY COEFFICIENT OF SLAG} COMPONENTS: like Si, C, Mn (wrt to $1 \mathrm{wt} \%$ standard state) is also calculated on the basis of the provided input data [1].
3.4 THERMODYNAMICS OF THE POSSIBLE REACTION REACTIONS OF Si HEARTH[1] : This thermodynamic aspect of silicon in hearth is calculated on basis of the input data and taking the help of the following equations:

a. Slag-Metal reaction is given as: $\left(\mathrm{SiO}_{2}\right)+2[\mathrm{C}]=[\mathrm{Si}]+\mathbf{2 C O}(\mathrm{g})$ for which $\operatorname{LogK}=(-30935 / T)+20.455$

b. Silicon-Manganese reaction is given as: $(\mathrm{MnO})+[\mathrm{Si}]=2[\mathrm{Mn}]+\left(\mathrm{SiO}_{2}\right) \quad$ for which $\operatorname{LogK}=2.8 * *\left((\% \mathrm{CaO}+\% \mathrm{MgO}) /\left(\% \mathrm{SiO}_{2}\right)-1.16\right.$ 3.5 THE DEADMANZONE (INACTIVE COKE ZONE): The un-reacted part of coke accumulates as a conical heap which gives mechanical support to overlying burden and permeability to molten iron and slag. This conical heap is called the deadman or the inactive coke zone. Here in the database, the height and volume of the conical heap is calculated based on the input data [1]

\subsection{FLOW RESISTANCE COEFFICIENT: This} parameter is an empirical parameter of the amount of resistance offered in various parts of the blast furnace. Flow resistance coefficient(FRC) is given as $\mathrm{FRC}=\Delta \mathrm{P} / \mathrm{Nominal}$ flow rate and of the total FRC $20 \%$ is from granular zone $50 \%$ from cohesive zone $30 \%$ from coke+ tueyre zone. In the database, the values of FRC's have been reduced by an order of 100000 for better analysis [1].

\section{THE CASE STUDY [2]}

Here an example the charge data of a large industrial blast furnace is taken which is fed into the p_bf_database and the output from the database is the validated against the existing output values [2].

CHARGE DATA: The daily charge to an iron blast furnace consisted of the following

a. Pellets: Weight 2400 tons

Composition : $86 \% \mathrm{Fe}_{2} \mathrm{O}_{3}, 9 \% \mathrm{SiO}_{2}, 0.6 \% \mathrm{CaO}, 0.5 \% \mathrm{Al}_{2} \mathrm{O}_{3}$ $, 0.4 \% \mathrm{FeO}, 0.4 \% \mathrm{MgO}, 0.25 \% \mathrm{MnO}, 0.04 \% \mathrm{P}_{2} \mathrm{O}_{5}, 0.01 \%$ $\mathrm{FeS}, 2.8 \% \mathrm{H}_{2} \mathrm{O}$

b. Sinter: Weight 2400 tons

Composition: $66 \% \mathrm{Fe}_{2} \mathrm{O}_{3}, 8.5 \% \mathrm{SiO}_{2}, 6 \% \mathrm{CaO}, 2 \% \mathrm{Al}_{2} \mathrm{O}_{3}$, $14 \% \mathrm{FeO}, 1 \% \mathrm{MgO}, 0.75 \% \mathrm{MnO}, 0.1 \% \mathrm{P}_{2} \mathrm{O}_{5}, 0.05 \% \mathrm{FeS}$ , $1.6 \% \mathrm{H}_{2} \mathrm{O}$

\section{c. Fluxes:}

i. Limestone: Weight 375 tons, Composition: $96.5 \% \mathrm{CaCO}_{3}$ $, 1.8 \% \mathrm{MgCO}_{3}, 0.7 \% \mathrm{Fe}_{2} \mathrm{O}_{3}, 0.5 \% \mathrm{Al}_{2} \mathrm{O}_{3}, 0.5 \% \mathrm{SiO}_{2}$

ii. Dolomite: Weight 375 tons Composition: $54.6 \% \mathrm{CaCO}_{3}$, $43.8 \% \mathrm{MgCO}_{3}, 0.6 \% \mathrm{Fe} 2 \mathrm{O} 3,0.5 \% \mathrm{Al}_{2} \mathrm{O}_{3}, 0.5 \% \mathrm{SiO}_{2}$

d. Fuel: Coke Weight 1875 tons

Composition: $87 \% \mathrm{C}, 3.5 \% \mathrm{SiO}_{2}, 2.5 \% \mathrm{Al}_{2} \mathrm{O}_{3}, 1.5 \% \mathrm{FeS}$, $0.4 \% \mathrm{CaO}, 0.1 \% \mathrm{MgO}, 5 \% \mathrm{H}_{2} \mathrm{O}$.

e. Amount of blast supplied: $5850000 \mathrm{~m}^{3} /$ day at $37^{\circ} \mathrm{C}$ and 1 $\mathrm{atm}$. The moisture content is $30 \mathrm{~g} / \mathrm{m}^{3}$ 
f. FLUE-DUST: Weight: 65 tons

Composition: $60 \% \mathrm{Fe}_{2} \mathrm{O}_{3}, 18.5 \% \mathrm{C}, 8 \% \mathrm{SiO}_{2}, 8.5 \% \mathrm{CaCO}_{3}$ $, 3.5 \% \mathrm{MgCO}_{3}, 1.5 \% \mathrm{Al}_{2} \mathrm{O}_{3}$

\subsection{VALIDATON and RESULTS of p_bf_database:}

The input charge value fed in the database:

All the Phosphorus charged, one-half of Mn, one-seventh of

Si and one-tenth of Sulphur enters the pig iron[2].

\section{TEMPERATURE AND HEAT PARAMETERS [2]:}

1. The blast is pre-heated at $777^{\circ} \mathrm{C}$

2. The Solid Charge is at $25^{\circ} \mathrm{C}$

3. Top gasses from the furnace are at $170{ }^{\circ} \mathrm{C}$

4. The pig-iron is at $1490{ }^{\circ} \mathrm{C}$

5. The slag temperature is $1550{ }^{\circ} \mathrm{C}$

1 ton pig iron is taken as basis of calculation and $298^{\circ} \mathrm{K}$ is taken as the reference temperature.

\section{HEAT SUPPLY:}

a. Sensible heat of pre-heated blast.

b. Sensible heat of solid charge(negligible)

c. Heat generated by exothermic reaction.

\section{HEAT CONSUMPTION:}

a. Heat absorbed by the endothermic reactions.

b. Sensible heat in pig iron

c. Sensible heat in slag

d. Sensible heat in top gasses

e. Sensible heat in flue dust

f. Heat losses

\section{ADDITIONAL PARAMETERS}

These additional parameters are being taken from the suitable literature which can best mach the existing charge and heat data.

1. Nominal velocity of gas through bed

2. Bed void fraction

3. Average density of ore

4. Average density of coke

5. Average density of flux

Temperature of the Stack

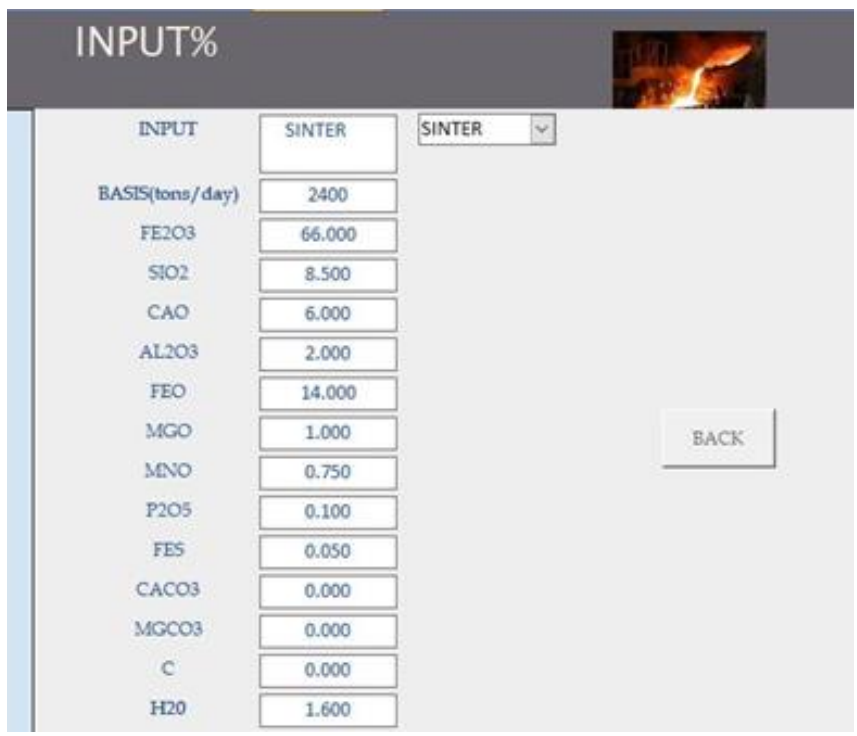

Fig-14
The figure is the INPUT\% interface here details of SINTER id displayed, in similar fashion, input details of PELLETS, FLUXES, and COKE if fed to the database. Similarly the blast-feed parameters are entered:

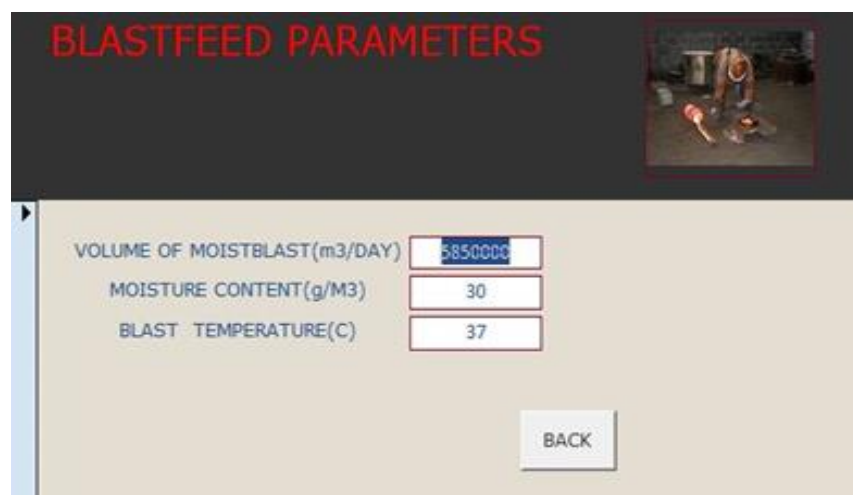

Fig-15

After giving the blast-feed parameters the following blast calculations is obtained

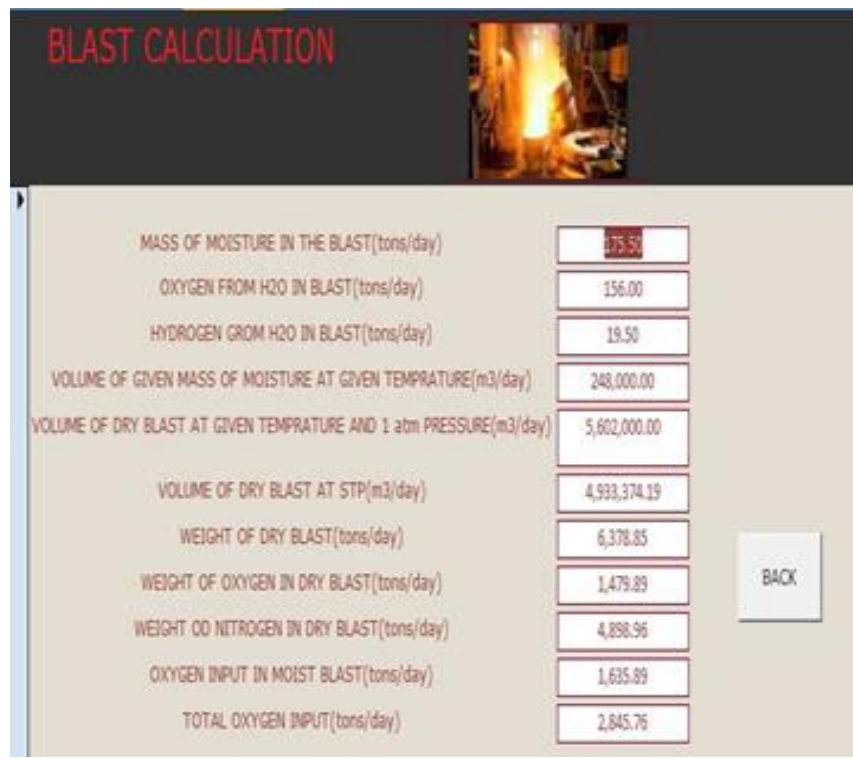

Fig-16

Once the input data is fed into the database, one can now see the output values by making some changes in the parameters (if required).

\subsubsection{The Output:}

One has to set the parameters of the PIG IRON:

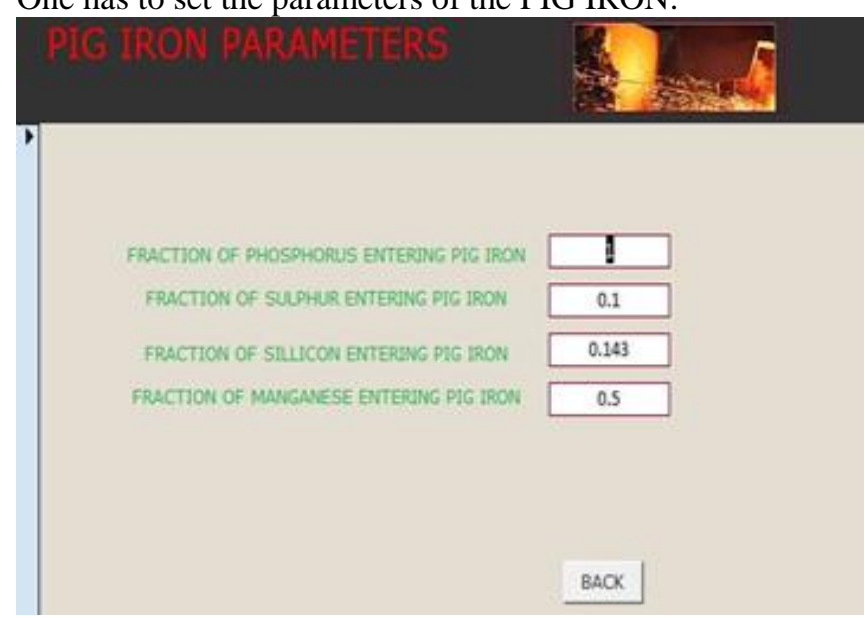

Fig-17 
4.1.2 PIG IRON ANALYSIS: Here, the composition, temperature, Viscosity, density etc. Of the pig iron can be seen and analysed.

Output from database:

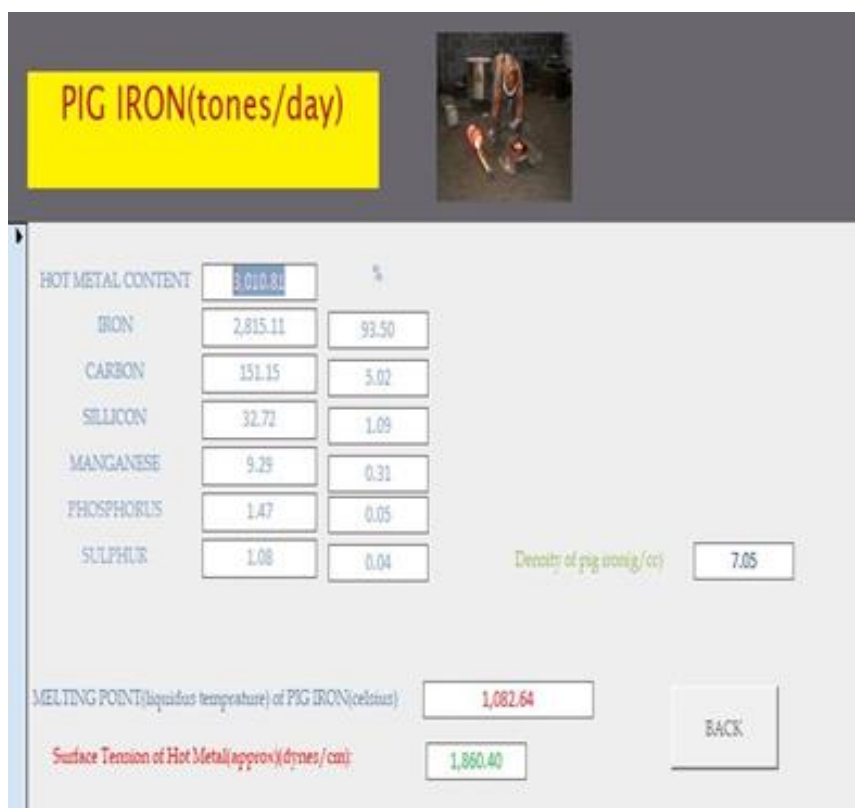

Fig-18

Output from known literature [2]: PIG IRON (3010

Tons/day)

\begin{tabular}{|c|c|}
\hline 2814.8 & 93.50 \\
\hline 150.5 & 5.00 \\
\hline 32.9 & 1.09 \\
\hline 9.3 & 0.30 \\
\hline 1.52 & 0.05 \\
\hline 1.08 & 0.035 \\
\hline
\end{tabular}

Table-1

4.1.3 SLAG: Here the slag composition and Slag Basicity can be seen: Output from Database:
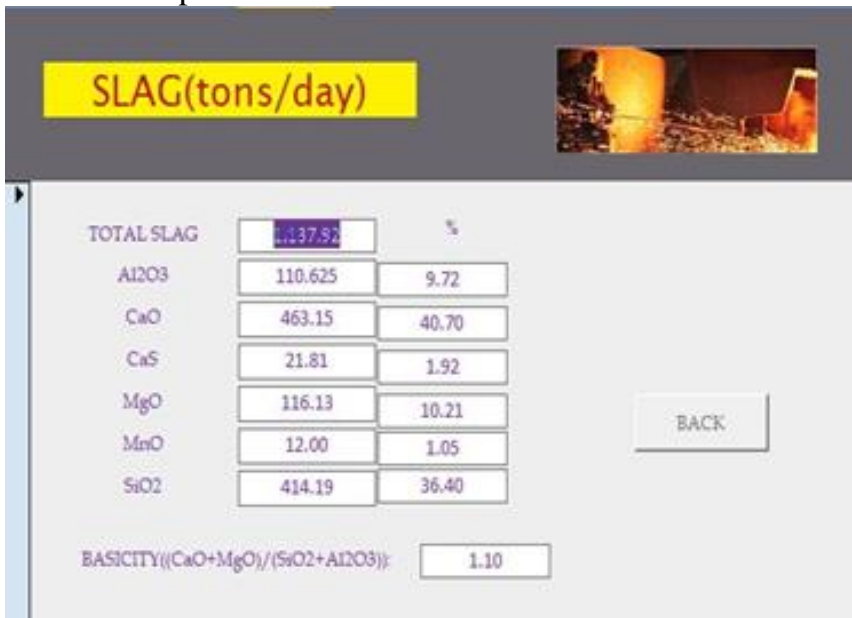

Fig-19

Output from Known Literature [2]:

SLAG (1136.5 Tons/day)

\begin{tabular}{|c|c|c|}
\hline Constituents & Amount(Tons/day) & Composition(\%) \\
\hline Al2O3 & 109.5 & 9.63 \\
\hline CaO & 463.3 & 40.76 \\
\hline Cas & 21.8 & 1.92 \\
\hline MgO & 116.2 & 10.23 \\
\hline MnO & 12.0 & 1.06 \\
\hline SiO2 & 413.7 & 36.40 \\
\hline
\end{tabular}

Table-2

4.1.4 Top Gasses: Output from Database

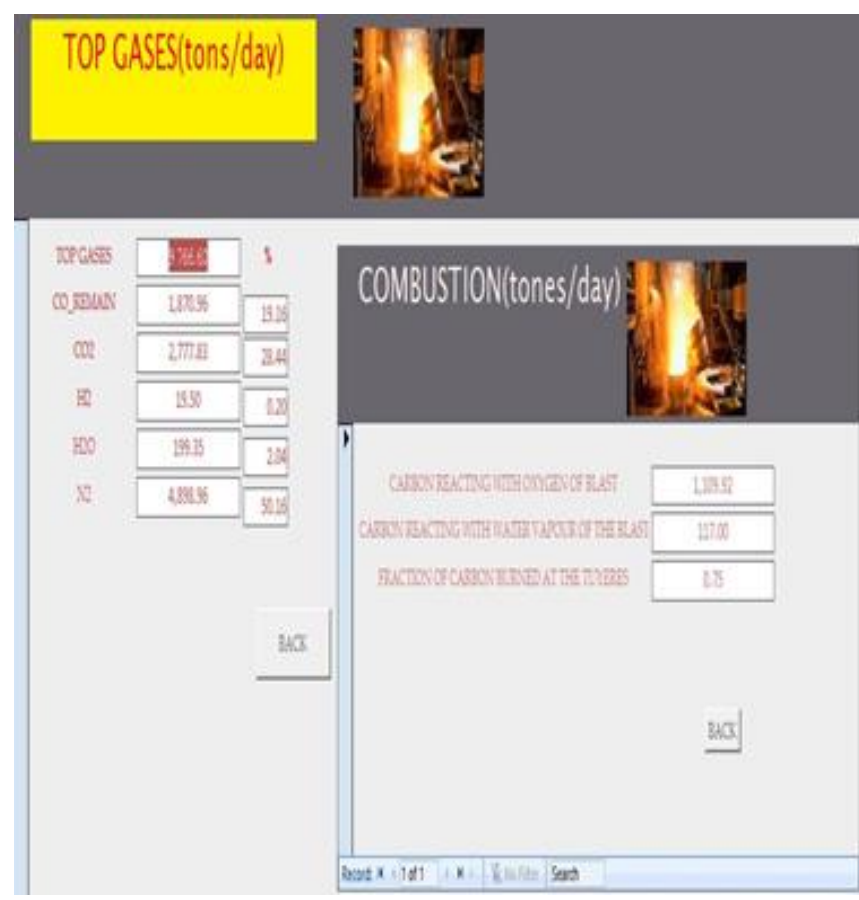

Fig-20

Output from Known Literature [2]:

Top Gasses (9769 Tons/day)

\begin{tabular}{|c|c|c|}
\hline Constituents & Amount(Tons/day) & Composition(\%) \\
\hline CO(remaining) & 1871.5 & 19.16 \\
\hline C02 & 2778.6 & 28.44 \\
\hline H2 & 19.5 & 0.20 \\
\hline H20 & 199.4 & 2.04 \\
\hline N2 & 4900.0 & 50.16 \\
\hline
\end{tabular}

Table-3

\begin{tabular}{|c|c|}
\hline $\begin{array}{c}\text { Carbon reacting with oxygen from } \\
\text { the blast }\end{array}$ & $\mathbf{1 1 1 0}$ tons/day \\
\hline $\begin{array}{c}\text { Carbon reacting with water vapour } \\
\text { of blast }\end{array}$ & 117.0 tons/day \\
\hline Total carbon in coke & 1631 tons/day \\
\hline Fraction of carbon burned at tuyeres & 0.7520 \\
\hline
\end{tabular}

Table-4

So it can be clearly seen that the output data from the database model is in almost complete agreement from that of the data available in literature.

\subsection{THE ADDITIONAL FEATURES:}

The user has to feed the aerodynamic features to the database: 


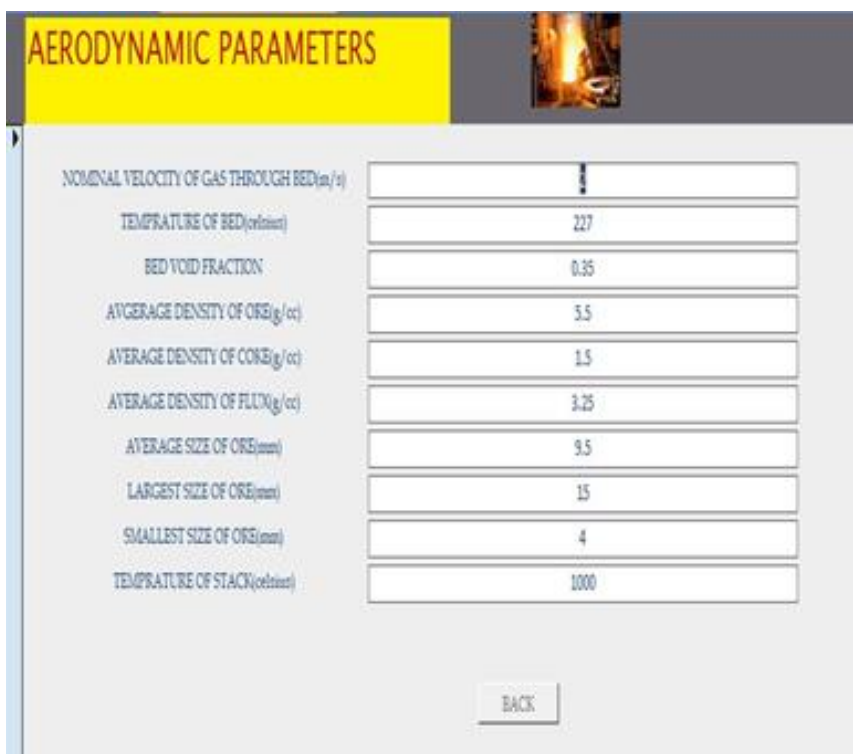

Fig-21

From here as the output the user can see the:

\subsubsection{AERODYNAMIC FEATURES OF BLAST FURNACE:}

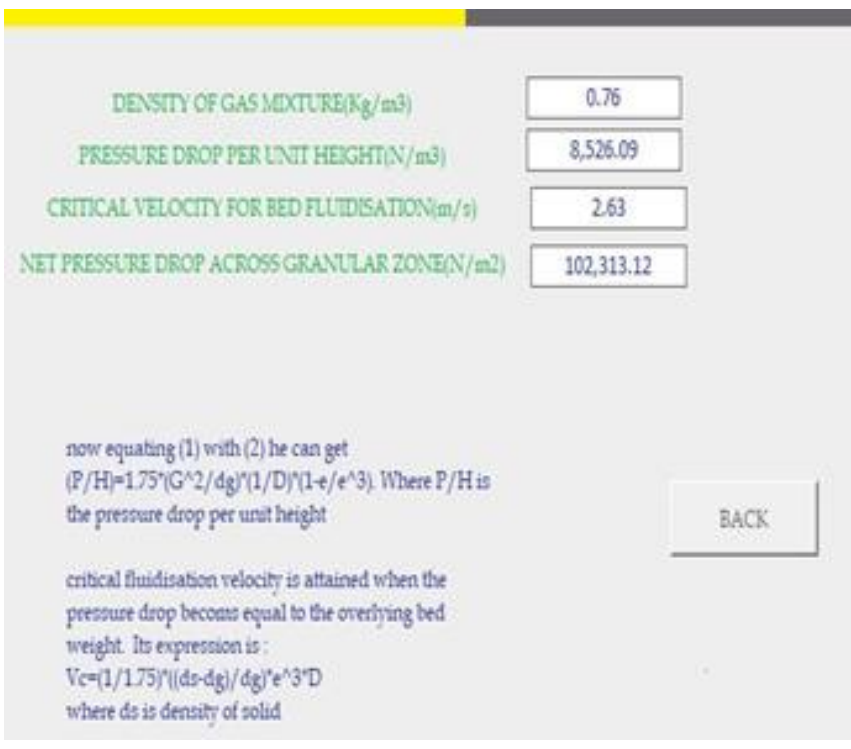

Fig-22

4.2.2 RAFT CALCULATION: Here the calculations are based on the discussion of section 3:

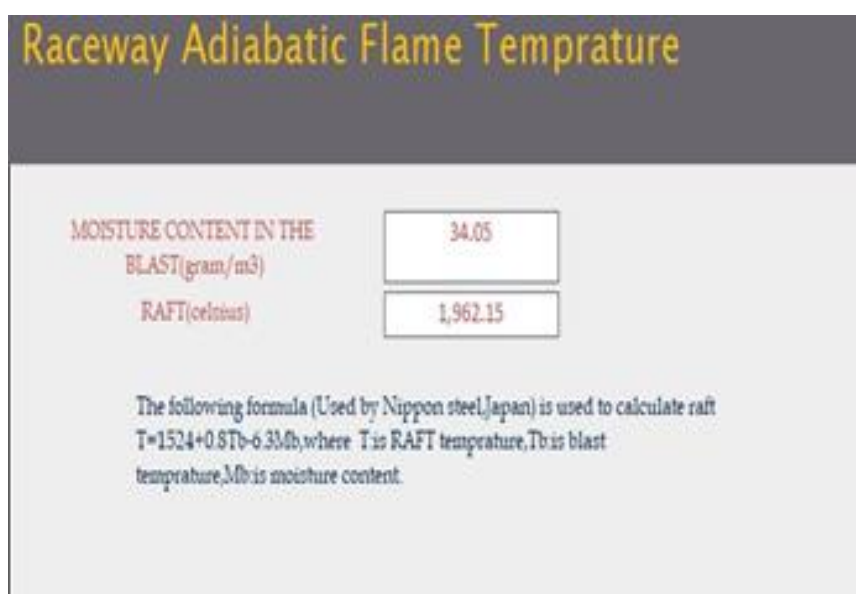

Fig-23

\subsubsection{THE DEADMAN ZONE}

\section{Volume of deadman zone}

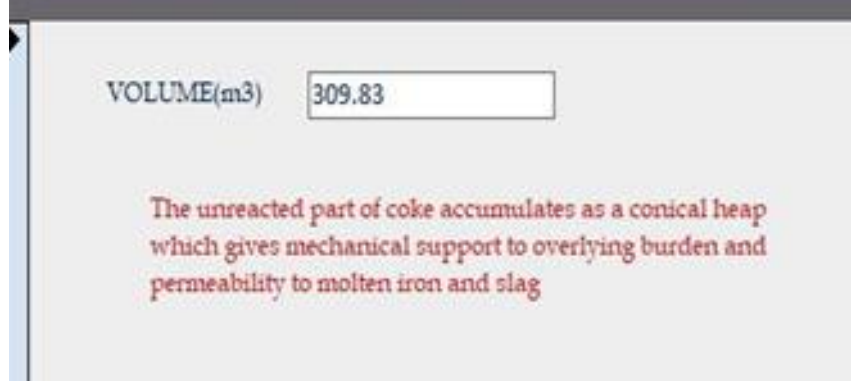

Fig-24

From the volume the height of the deadman zone is also found:

\section{Height of deadman zone}

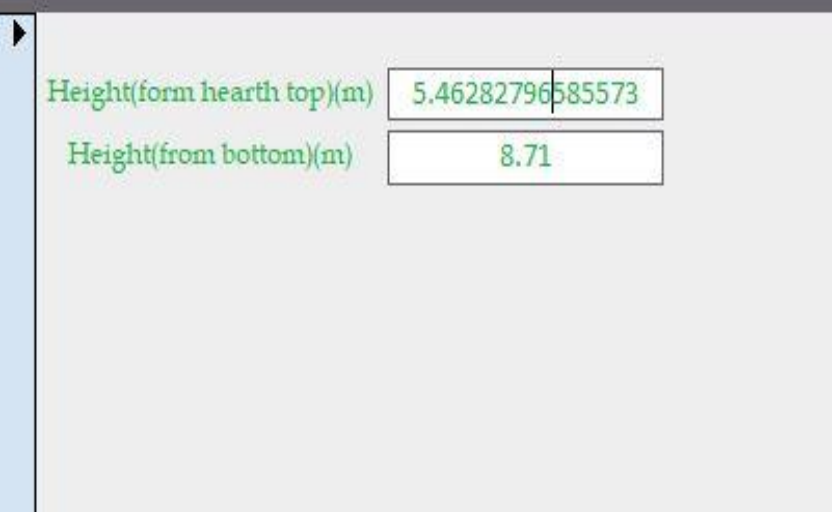

Fig-25

\section{CONCLUSION:}

The p_bf_database is correctly validated with the help of the existing data of the case study. The user can feed any combinations of data and can get the output. This is very useful in the sense that one can have a clear knowledge of the output (the help of this database model) before actual operation has started. So if the virtual output (from the database) is not as expected, the user can make the necessary changed and corrections in the input. Furthermore a prior knowledge of the possible output can make the plant process more robust and efficient.

Future Scope: This database model can be aided with the intelligent techniques of artificial intelligence, like that of the algorithms of machine learning and the artificial neural networks. Here one can make the system to learn in order to decide that input-output combination which is most profitable in terms of quantity and quality.

\section{ACKNOLEDGEMENT}

I, Gaurav Kumar, Corresponding author of the paper would like to sincerely acknowledge and express my deep gratitude to Mr. Rabindranath Ray, Former Associate Professor (Metallurgical and Materials Engineering Department) NIT DURGAPUR (W.B) India. For his technical and moral 
guidance during the period of my preparation of the database model. He has been always helpful and always encouraged me to complete my work. His class lectures and notes also gave me a whole lot of knowledge of the mass and heat balance, extractive metallurgy and industrial analysis. I am very grateful to him for his help and guidance.

\section{REFERENCES}

[1] Ghosh, A., Chatterjee, A. "IRONMAKING AND STEELMAKING" Eastern Economy Edition, Pg49-80,101-110,111-118, 130- 132, 134-136, 179-184

[2] RAO, Y.K, “METALLURGICAL THERMODYNAMICS” Pg 35-40, 201-205 